\title{
Evaluation of Risk of Injury by Extravasation of Hyperosmolar and Vasopressor Agents in a Rat Model
}

\author{
Yuuka Shibata, ${ }^{* a}$ Yumeka Sagara, ${ }^{b}$ Tomoharu Yokooji, ${ }^{b}$ Takanori Taogoshi, ${ }^{a}$ Maiko Tanaka, ${ }^{c}$ \\ Michihiro Hide, ${ }^{d}$ and Hiroaki Matsuo ${ }^{a}$ \\ ${ }^{a}$ Department of Pharmaceutical Services, Hiroshima University Hospital; 1-2-3 Kasumi, Minami-ku, Hiroshima \\ 734-8551, Japan: ${ }^{b}$ School of Pharmaceutical Sciences, Hiroshima University; 1-2-3 Kasumi, Minami-ku, Hiroshima \\ 734-8551, Japan: ${ }^{c}$ Department of Dermatology, Mazda Hospital; 2-15 Aosakiminami, Fuchu-cho, Aki-gun, \\ Hiroshima 730-8670, Japan: and ${ }^{d}$ Department of Dermatology, Graduate School of Biomedical and Health Sciences, \\ Hiroshima University; 1-2-3 Kasumi, Minami-ku, Hiroshima 734-8551, Japan. \\ Received February 9, 2018; accepted March 14, 2018
}

\begin{abstract}
Inadvertent leakage of noncytotoxic agents causes severe tissue injury. In this study, we macroscopically and histopathologically evaluated the extent of skin injury caused by extravasation of hyperosmolar or vasopressor agents in rats. Rats were intradermally administered saline $(100 \mu \mathrm{L})$, the hyperosmolar agents mannitol $(5-20 \mathrm{mg} / 100 \mu \mathrm{L})$ and glucose $(5-50 \mathrm{mg} / 100 \mu \mathrm{L})$, or the vasopressors dopamine $(2 \mathrm{mg} / 100 \mu \mathrm{L})$, adrenaline $(0.1 \mathrm{mg} / 100 \mu \mathrm{L})$, and noradrenaline $(0.1 \mathrm{mg} / 100 \mu \mathrm{L})$. Lesion size (erythema, induration, ulceration, and necrosis) was monitored after agent injection. Skin tissue biopsies were evaluated at $24 \mathrm{~h}$ after agent injection. Mannitol and glucose induced severe lesions in a concentration (and osmolarity)-dependent manner. Mannitol and glucose at $\mathbf{1 0 - 2 0 \%}(\mathrm{w} / \mathrm{v})$ induced inflammation, and lesions healed within 3-6d. In contrast, $\geq 25 \%$ (w/v) glucose elicited severe skin lesions with ulceration and necrosis within $24 \mathrm{~h}$, which healed gradually 16-22 d after injection. The severity of extravasation injury caused by vasopressors varied. Adrenaline and noradrenaline induced severe injury with ulceration and necrosis, which healed over 23.3 and $18.3 \mathrm{~d}$, respectively. In contrast, dopamine induced erythema and induration, and damage duration was only $5.7 \mathrm{~d}$. In conclusion, mannitol and glucose at osmolarities of 549-1098 and 833-1110 $\mathrm{mOsm} / \mathrm{L}$, respectively, can be classified as "irritants," while $\geq \mathbf{1 3 8 8} \mathrm{mOsm} / \mathrm{L}$ glucose can be classified as a "vesicant." As for vasopressors, adrenaline and noradrenaline can be classified as "vesicants" whereas dopamine can be classified as an "irritant."
\end{abstract}

Key words extravasation; vasopressor; hyperosmolar; noncytotoxic

Inadvertent vascular leakage of medications is a major iatrogenic cause of injury, especially severe tissue injury. Most instances of extravasation injury are caused by cytotoxic agents. Therefore, several guidelines have been issued on the prevention and treatment of extravasation injury by cytotoxic agents. In these guidelines, cytotoxic agents are classified into three categories according to the severity of skin injury after extravasation: vesicants, irritants, and non-tissue-damaging agents. ${ }^{1-3)}$ Vesicants are agents that cause tissue necrosis even at small volumes of extravasation owing to their inherent toxicity to cells. Irritants cause inflammation without necrosis at the extravasation site. Non-tissue-damaging agents do not induce tissue injury at all. By careful monitoring according to severity of potential iatrogenic effects, the incidence of extravasation injury induced by cytotoxic agents has decreased. ${ }^{3)}$ In contrast, the number of case reports of severe extravasation injury caused by noncytotoxic agents are increasing as the mechanism of injury induced by extravasation of noncytotoxic agents is incompletely understood compared with that of cytotoxic agents.

With respect to the mechanism of tissue damage by extravasation of noncytotoxic agents, high osmolarity, acidic or alkaline $\mathrm{pH}$, and/or vasoconstrictive activity have all been suggested as the cause of severe extravasation injury among noncytotoxic agents. ${ }^{4,5)}$ Mannitol is generally used as an osmotic diuretic agent to increase urinary excretion and reduce elevated intracranial pressure following head injuries. ${ }^{6}$ As mannitol solutions (15-20\% (w/v)) exhibit hyperosmolarity
(824-1098 mOsm/L), extravasated mannitol can cause swelling and severe edema by drawing fluid into the tissue. ${ }^{7)}$ In addition, extravasation of $>10 \%(\mathrm{w} / \mathrm{v})(555 \mathrm{mOsm} / \mathrm{L})$ glucose can cause tissue injury by dysregulating the equilibrium between intracellular and extracellular fluid. Inadvertent leakage of these agents has been reported to cause reduced blood flow, tissue necrosis, and nerve damage. ${ }^{8)}$ In such cases, emergency fasciotomy, skin grafting, wound debridement, or even limb amputation may be needed.9,10) Furthermore, hyperosmolar agents are high risk agents for the induction of phlebitis. However, the mechanism of phlebitis might be different from that of extravasation injury. Phlebitis is thought to be caused by the disruption of vascular endothelial cells, whereas extravasation injury is caused by the disruption of dermal cells and skin muscle cells. As many previous reports have revealed the extent to which osmolarity causes phlebitis in peripheral veins, ${ }^{11,12)}$ the permissible osmolarity for peripheral intravenous transfusions was determined based on the prevention of phlebitis in clinical situations. However, it is unclear what osmolarity causes extravasation injury.

Catecholamines such as dopamine, adrenaline and noradrenaline are commonly used as vasopressors in emergencies to improve critical hemodynamic instability. The American Heart Association guidelines recommend the use of a central venous line for catecholamine administration to prevent extravasation injury. ${ }^{13)}$ However, in emergencies, catecholamine may be administered using a peripheral line, as a peripheral line is more easily available compared with a central venous 
line, and critical hemodynamic instability should be improved as soon as possible. Furthermore, catecholamines are forcefully administered by constant infusion using automated syringe drivers, except for when administered as a single intravenous bolus injection against cardiac arrest. Thus, the risk of extravasation injury induced by catecholamines may be relatively high. However, the extent of extravasation injuries is incompletely understood because data are limited to a few case reports. Hence, it is important to recognize the potential risks for tissue injury caused by extravasation of nontoxic agents. In this study, we macroscopically and histopathologically evaluated the extent of extravasation injuries induced by hyperosmolar agents and vasopressors using a rat model. Moreover, we classified these agents into three categories (irritants, vesicants, or non-tissue damaging agents) based on the degree of skin damage.

\section{MATERIALS AND METHODS}

Animals All experiments were carried out in accordance with the Guide for Animal Experimentation from the Committee of Research Facilities for Laboratory Animal Sciences of Hiroshima University (permit number: A15-31). Fifty-four male Wistar rats ( 8 weeks old; body weight, 250-270 g) were purchased from Japan SLC, Inc. (Shizuoka, Japan). Rats were housed in individual cages in a temperature-controlled room at $23^{\circ} \mathrm{C}$ on a 12 -h light-dark cycle. They received a standard laboratory diet (MF, Oriental Yeast Company, Tokyo, Japan) and water ad libitum for $>1$ week before experiments.

Extravasation Models Rats were anesthetized with medetomidine $(0.15 \mathrm{mg} / \mathrm{kg})$, midazolam $(2.0 \mathrm{mg} / \mathrm{kg})$, and butorphanol $(2.5 \mathrm{mg} / \mathrm{kg})$ injected intraperitoneally. Extravasation studies were performed according to previous reports. ${ }^{14,15)}$ Briefly, rats were assigned randomly to eighteen experimental groups of three rats each. The hair on their backs was shaved with electrical clippers (Thrive 2100; Daito Electric Machine Industry Co., Ltd., Osaka, Japan). Twenty-four hours after hair removal, rats with no wounds were injected intradermally (i.d.) with $100 \mu \mathrm{L}$ of hyperosmotic agent or vasopressor (the minimum volume at which lesions can be observed macroscopically). As a negative control group, $100 \mu \mathrm{L}$ physiological $(0.9 \%)$ saline $(\mathrm{pH} 4.5-8.0)$ was injected i.d. To evaluate the effect of osmotic pressure on the severity of extravasation injury, mannitol (Yoshindo Inc., Toyama, Japan) and glucose (Otsuka Pharmaceutical Factory Inc., Tokushima, Japan) were used as pharmacologically inactive, noncytotoxic agents. Twenty percent (w/v) mannitol and 50\% (w/v) glucose were diluted to $5-15 \%(\mathrm{w} / \mathrm{v})$ and $5-40 \%(\mathrm{w} / \mathrm{v})$ with water for injection, respectively. When their osmolarities were calculated, $20 \%(\mathrm{w} / \mathrm{v})$ mannitol and 50\% (w/v) glucose have osmolarities of 1098 and $2775 \mathrm{mOsm} / \mathrm{L}$, respectively. Clinical concentrations of the vasopressors dopamine $(20 \mathrm{mg} / \mathrm{mL}, \mathrm{pH} 3.0-5.0$; Kyowa Hakko Kirin Co., Ltd., Tokyo, Japan), adrenaline (1 mg/mL, pH 2.3-5.0; Daiichi Sankyo Co., Ltd., Tokyo, Japan), and noradrenaline (1 mg/mL, pH 2.3-5.0; Daiichi Sankyo Co., Ltd.) were used. To exclude the effect of $\mathrm{pH}$ on extravasation injury, saline solution was adjusted to $\mathrm{pH} 3.0$ and 5.0 with hydrochloric acid and injected as controls. Intradermal injections using a $26-\mathrm{G}$ needle were performed after pinching the dorsal skin at the center of a hair-free site $7 \mathrm{~cm}$ from the ear. Two injections were made, on axisymmetric dor- sal sides of each rat. Right-hand side lesions were macroscopically monitored until the injury healed completely. Left-hand side lesions were punch-biopsied under anesthesia using a dermal punch (Maruho, Osaka, Japan) with a diameter of $4 \mathrm{~mm}$ at $24 \mathrm{~h}$ after intradermal injection in accordance with the peak time of lesion severity in a previous report on histopathological evaluation of extravasation injury. ${ }^{16)}$

Macroscopic Evaluation Extravasation injury to skin was evaluated macroscopically according to a previously described method. ${ }^{14)}$ Briefly, the widest perpendicular diameters of skin lesions were measured using a caliper. The area of lesion sites was calculated in $\mathrm{cm}^{2}$ as the product of diameters. ${ }^{14)}$ Each lesion site was inspected every day during the first week after intradermal injection, then every $5 \mathrm{~d}$ from day 7 . Four lesion parameters (erythema, induration, ulceration, necrosis) were assessed. The area under the lesion-time curve (AUC) was calculated in $\mathrm{cm}^{2}$ days using the trapezoidal method. ${ }^{14)}$ The $A U C$, peak area of the lesion, and damage duration were analyzed until the injury healed completely.

Histopathological Evaluation Tissue samples obtained by biopsy were fixed in 10\% formaldehyde before dehydration, then sections ( $5 \mu \mathrm{m}$ thick) from the paraffin-embedded tissue blocks were stained with hematoxylin and eosin and evaluated under a light microscope (BX51; Olympus, Tokyo, Japan). Each sample was analyzed by independent pathologists blinded to the experimental procedure.

Statistical Analyses Data are presented as the mean \pm standard deviation (S.D.). Differences among treatment groups were analyzed using ANOVA followed by the Student-Newman-Keuls multiple-comparison post hoc test. A value of $p<0.05$ was considered to indicate statistically significant differences.

\section{RESULTS}

Macroscopic Findings Saline-injected rats showed slight erythema at injection sites that disappeared within $1.3 \mathrm{~d}$ (Table 1). Mannitol or glucose injection immediately induced ovoid swollen skin lesions that reached maximal size within $24 \mathrm{~h}$. In these rats, mannitol or glucose administration induced severe lesions, such as ulceration, in a concentration (and osmolarity)-dependent manner (Table 1). Mannitol and glucose at $\leq 20 \%$ (w/v) induced erythema, but no ulceration, and erythema lesions healed within $0.7-6 \mathrm{~d}$. In contrast, $\geq 25 \%$ (w/v) glucose elicited severe skin lesions with ulceration within $24 \mathrm{~h}$ that healed 17-22 d after injection. In mannitol-injected rats, the peak area and $A U C$ of lesions increased significantly at $\geq 15 \%$ (w/v) and the damage duration was extended at $\geq 10 \%$ (w/v) compared with the saline-injected rats. In contrast, in glucose-injected rats, the peak area of lesions also increased significantly at $\geq 15 \%(\mathrm{w} / \mathrm{v})$, but extended duration of damage was observed only at $\geq 25 \%(\mathrm{w} / \mathrm{v})$. These results indicate that glucose-induced lesions were slightly less severe compared with those induced by mannitol at the same concentration.

Next, we examined the extent of extravasation skin injury induced by three vasopressors; dopamine, adrenaline and noradrenaline. All vasopressors induced maximal skin lesions within $24 \mathrm{~h}$ and the peak area was similar among the three agents (Table 2). However, the severity of extravasation injury differed. Dopamine induced erythema and induration, with no ulceration, which healed within $5.7 \mathrm{~d}$, whereas adrenaline and 
Table 1. Effects of Osmolarity on Mannitol- and Glucose-Induced Skin Lesions in Rats

\begin{tabular}{|c|c|c|c|c|c|c|c|}
\hline Agents & $\begin{array}{c}\text { Concentration } \\
(\%(\mathrm{w} / \mathrm{v}))\end{array}$ & $\begin{array}{l}\text { Osmolarity } \\
(\mathrm{mOsm} / \mathrm{L})\end{array}$ & $\begin{array}{l}\text { Macroscopic } \\
\text { findings }\end{array}$ & $\begin{array}{l}\text { Histopathological } \\
\text { findings }\end{array}$ & $\begin{array}{l}\text { Peak area } \\
\left(\mathrm{cm}^{2}\right)\end{array}$ & $\begin{array}{c}A U C \\
\left(\mathrm{~cm}^{2} \mathrm{~d}\right)\end{array}$ & $\begin{array}{l}\text { Damage duration } \\
\text { (d) }\end{array}$ \\
\hline Saline & 0.9 & 286 & $\mathrm{E}$ & $\mathrm{NC}$ & $0.14 \pm 0.14$ & $0.16 \pm 0.16$ & $1.3 \pm 1.2$ \\
\hline \multirow[t]{4}{*}{ Mannitol } & 5 & 274 & $\mathrm{E}$ & $\mathrm{NC}$ & $0.24 \pm 0.04$ & $0.35 \pm 0.14$ & $2.3 \pm 0.6$ \\
\hline & 10 & 549 & $\mathrm{E}$ & ES, IIC & $0.36 \pm 0.17$ & $0.77 \pm 0.32$ & $5.7 \pm 0.6 * *$ \\
\hline & 15 & 823 & $\mathrm{E}$ & ES, IIC & $0.47 \pm 0.02 * *$ & $1.04 \pm 0.46^{*}$ & $5.3 \pm 1.5^{* *}$ \\
\hline & 20 & 1098 & $\mathrm{E}$ & ES, IIC & $0.54 \pm 0.06^{* *}$ & $0.97 \pm 0.30 *$ & $3.7 \pm 0.6^{*}$ \\
\hline \multirow[t]{8}{*}{ Glucose } & 5 & 278 & $\mathrm{E}$ & $\mathrm{NC}$ & $0.04 \pm 0.07$ & $0.05 \pm 0.09$ & $0.7 \pm 1.2$ \\
\hline & 10 & 555 & $\mathrm{E}$ & ES, IIC & $0.28 \pm 0.05$ & $0.44 \pm 0.11$ & $3.3 \pm 0.6$ \\
\hline & 15 & 833 & $\mathrm{E}$ & ES, IIC & $0.38 \pm 0.03 *$ & $0.82 \pm 0.45$ & $5.0 \pm 2.6$ \\
\hline & 20 & 1110 & $\mathrm{E}$ & ES, IIC & $0.55 \pm 0.07 * *$ & $0.93 \pm 0.42$ & $3.3 \pm 1.2$ \\
\hline & 25 & 1388 & $\mathrm{E}, \mathrm{I}, \mathrm{U}$ & ES, IIC, DCF, NEC & $0.59 \pm 0.05 * *$ & $2.40 \pm 0.23 * *$ & $16.7 \pm 5.8 * *$ \\
\hline & 30 & 1665 & E, I, U & ES, IIC, DCF, NEC & $0.52 \pm 0.07 * *$ & $2.53 \pm 0.50 * *$ & $16.7 \pm 2.9 * *$ \\
\hline & 40 & 2220 & E, I, U & ES, IIC, DCF, NEC & $0.50 \pm 0.10 * *$ & $4.30 \pm 1.17 * *$ & $21.7 \pm 5.8 * *$ \\
\hline & 50 & 2775 & $\mathrm{E}, \mathrm{I}, \mathrm{U}$ & ES, DCF, NEC & $0.51 \pm 0.14 * *$ & $5.01 \pm 1.49 * *$ & $21.7 \pm 2.9 * *$ \\
\hline
\end{tabular}

Abbreviations: $A U C$, area under the lesion-time curve; E, erythema; I, induration; U, ulceration; NC, no change; ES, epidermal shedding; IIC, infiltration of inflammatory cells; DCF, degeneration of collagen fibers; NEC, necrosis. Each hyperosmolar agent was administered intradermally at a volume of $100 \mu \mathrm{L}$. Lesions were monitored until the injury was completely healed. Each value represents the mean \pm S.D. of results from three rats. $* p<0.05, * * p<0.01$ compared with saline treated rats.

Table 2. Evaluation of Extravasation Injuries Induced by Vasopressors or Low pH Solution in Rats

\begin{tabular}{lcccccc}
\hline \hline \multicolumn{1}{c}{ Agents } & $\mathrm{pH}$ & Macroscopic findings & Histopathological findings & Peak area $\left(\mathrm{cm}^{2}\right)$ & $A U C\left(\mathrm{~cm}^{2} \mathrm{~d}\right)$ & Damage duration $(\mathrm{d})$ \\
\hline Saline & $4.5-8.0$ & E & NC & $0.14 \pm 0.14$ & $0.16 \pm 0.16$ & $1.3 \pm 1.2$ \\
Dopamine $(20 \mathrm{mg} / \mathrm{mL})$ & $3.0-5.0$ & E, I & ES, IIC & $0.37 \pm 0.22$ & $0.36 \pm 0.09$ & $5.7 \pm 3.8$ \\
Adrenaline $(1 \mathrm{mg} / \mathrm{mL})$ & $2.3-5.0$ & E, I, U & ES, IIC, DCF, NEC & $0.32 \pm 0.07$ & $2.60 \pm 0.62^{* *}$ & $23.3 \pm 2.9 * *$ \\
Noradrenaline $(1 \mathrm{mg} / \mathrm{mL})$ & $2.3-5.0$ & E, I, U & ES, IIC, DCF, NEC & $0.35 \pm 0.10$ & $3.01 \pm 1.01^{* *}$ & $18.3 \pm 2.9^{* *}$ \\
Saline pH 3.0 & 3.0 & E & NC & $0.16 \pm 0.11$ & $0.13 \pm 0.07$ & $2.0 \pm 1.0$ \\
Saline pH 5.0 & 5.0 & E & NC & $0.04 \pm 0.07$ & $0.04 \pm 0.07$ & $0.7 \pm 1.2$ \\
\hline
\end{tabular}

Abbreviations: $A U C$, area under the lesion-time curve; E, erythema; I, induration; U, ulceration; NC, no change; ES, epidermal shedding; IIC, infiltration of inflammatory cells; DCF, degeneration of collagen fibers; NEC, necrosis. Saline with a pH of 3.0 or 5.0 was prepared by adding hydrochloric acid. Each solution was administered intradermally at a volume of $100 \mu \mathrm{L}$. Lesions were monitored until the injury was completely healed. Each value represents the mean \pm S.D. of results from three rats. $* * p<0.01$ compared with saline treated rats.
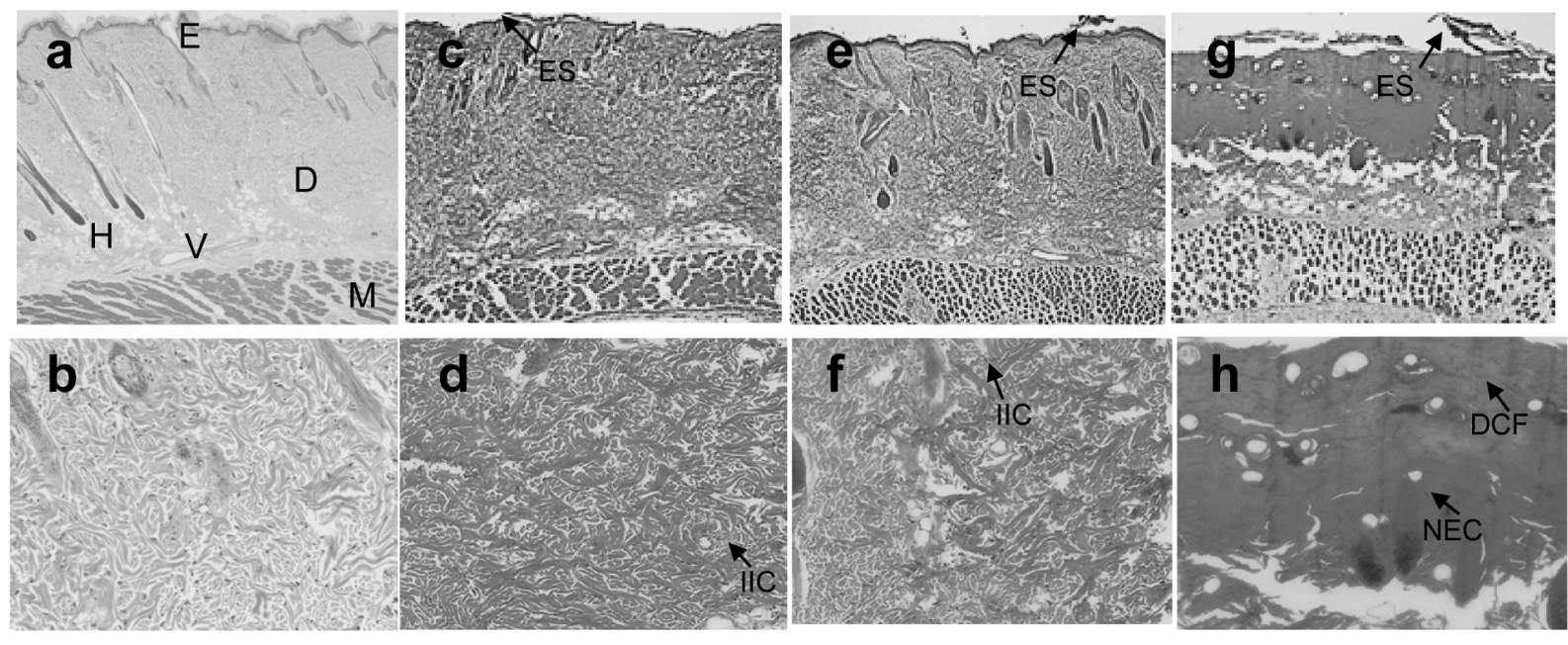

Fig. 1. Histopathology of Skin Lesions Induced by Extravasated Mannitol or Glucose in Rats

Control skin $(a, b)$ after intradermal (i.d.) injection of saline shows complete architectural construction of dermis, skin appendixes, epithelium (E), dermis (D), muscle $(\mathrm{M})$, hair follicles (H), and vessels (V). Injection of both mannitol (c, d) and glucose (e, f) at 15\% (w/v) resulted in epidermal shedding (ES), and infiltration of inflammatory cells (IIC) into dermis and skin muscle, but no necrosis (NEC). Glucose at $50 \%(\mathrm{w} / \mathrm{v})(\mathrm{g}, \mathrm{h})$ caused ES, degeneration of collagen fibers (DCF) and NEC in the deep dermis and muscle. Skin tissues were biopsied at $24 \mathrm{~h}$ after i.d. injection of saline, mannitol, or glucose. Hematoxylin and eosin staining: (a, c, e, g) magnification $\times 4$; (b, $\mathrm{d}, \mathrm{f}, \mathrm{h}$ ) magnification $\times 20$. Arrows point to the site of lesions.

noradrenaline induced ulceration, with a duration of 23.3 and $18.3 \mathrm{~d}$, respectively. This suggests that dopamine-induced lesions were much milder than those induced by adrenaline and noradrenaline. In this study, we used vasopressors dissolved in an acidic solution: dopamine, $\mathrm{pH} 3.0-5.0$; adrenaline, $\mathrm{pH}$ 2.3-5.0; noradrenaline, $\mathrm{pH}$ 2.3-5.0. Notably, it has been reported that extravasation of acidic solutions $(\mathrm{pH} 2.3-5.0)$ induces skin lesions. ${ }^{17)}$ To exclude the effect of the acidic $\mathrm{pH}$ of 

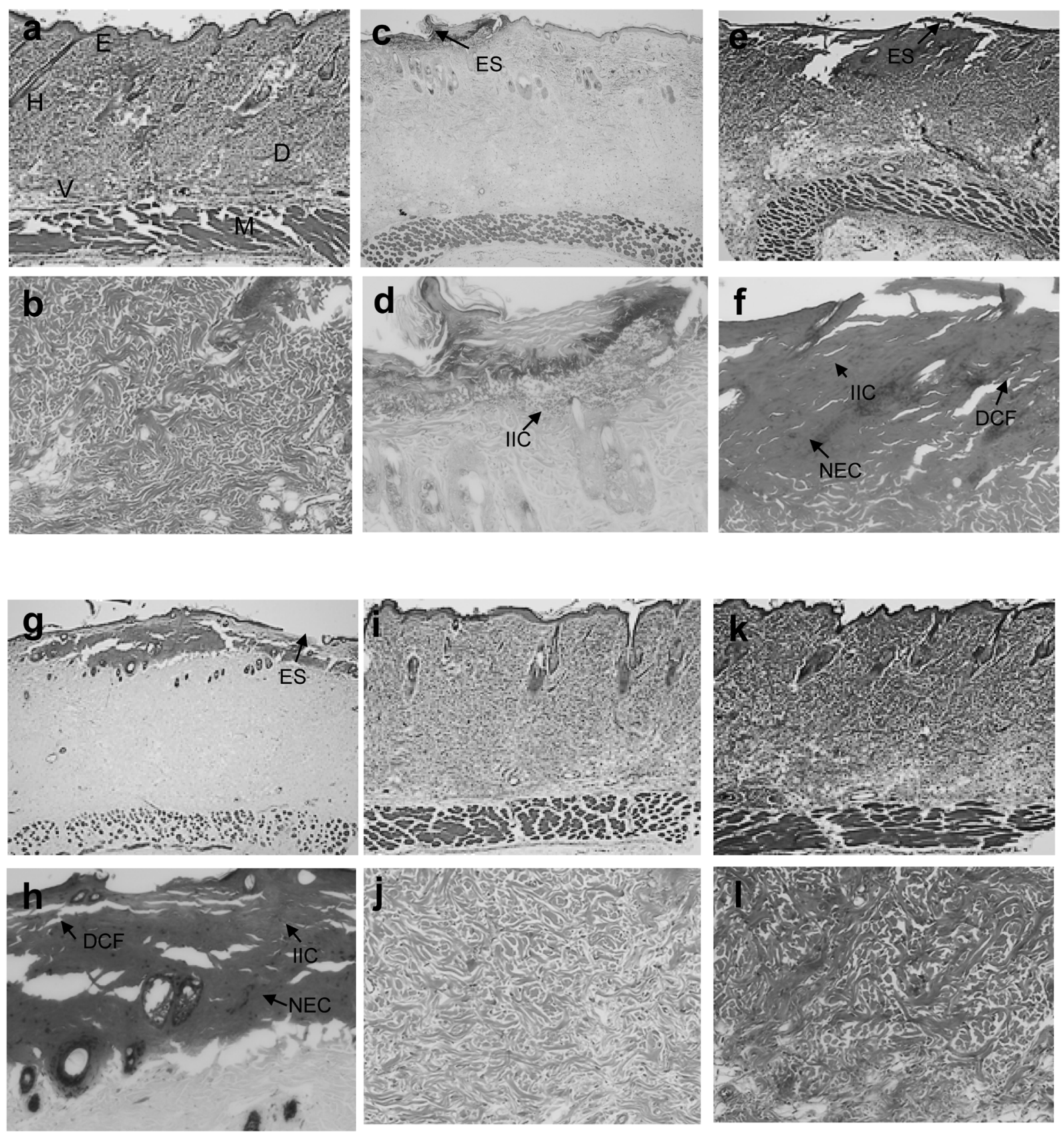

Fig. 2. Histopathology of Skin Lesions Induced by Extravasated Vasopressors in Rats

Control skin (a, b) after intradermal (i.d.) injection of saline shows complete architectural construction of dermis, skin appendixes, epithelium (E), dermis (D), muscle (M), hair follicles (H), and vessels (V). Dopamine injection (c, d) resulted in epidermal shedding (ES), and infiltration of inflammatory cells (IIC) into dermis and skin muscle, but no necrosis (NEC). Adrenaline (e, f) and noradrenaline ( $\mathrm{g}, \mathrm{h}$ ) injection caused ES, IIC into dermis and skin muscle, and degeneration of collagen fibers (DCF) and NEC in the deep dermis and muscle. Skin after injection of saline solutions at pH $3.0(\mathrm{i}, \mathrm{j})$ and $5.0(\mathrm{k}, \mathrm{l})$ showed complete architectural construction of the dermis. Skin tissues were biopsied at $24 \mathrm{~h}$ after i.d. injection of saline or vasopressors. Hematoxylin and eosin staining: (a, c, e, g) magnification $\times 4$; (b, d, f, h) magnification $\times 20$. Arrows point to the site of lesions.

the vasopressor solution on extravasation injury, we confirmed that acidic solutions do not induce extravasation injury. Notably, both $\mathrm{pH} 3.0$ and $\mathrm{pH} 5.0$ saline solutions did not induce indurations or ulcers, although erythema were seen. Furthermore, there were no significant differences in peak area, $A U C$, or damage duration between physiological $\mathrm{pH}$ and acidic $\mathrm{pH}$ saline solutions.

Histopathological Findings In saline-treated control rats, skin tissue specimens showed normal skin cells with intact architecture (Fig. 1). In good agreement with macroscopic findings, mannitol and glucose at $\leq 20 \%(\mathrm{w} / \mathrm{v})$ resulted in epidermal shedding, and inflammatory cell infiltration of dermis and skin muscle, but no necrosis (Table 1, Fig. 1). Notably, collagen degeneration, necrosis, and inflammatory cell infiltration of epidermal, dermal and subcutaneous tissues were evident at $24 \mathrm{~h}$ after injection of $\geq 25 \%$ (w/v) glucose (Table 1, Fig. 1). Injections of the three vasopressors caused bleeding, necrosis of vascular endothelial cells, epidermal shedding, and infiltration of inflammatory cells into the dermis and skin muscle. In addition, disruption and degeneration of collagen fibers were also observed in adrenaline- and noradrenaline-injected rats (Fig. 2). Rats injected with physiological $\mathrm{pH}, \mathrm{pH} 3.0$, and $\mathrm{pH}$ 5.0 saline exhibited regular morphology of skin tissue (Fig. 2). These morphological data are summarized in Table 2. 
Table 3. Vesicant Potential of Hyperosmolar and Vasopressor Agents

\begin{tabular}{clll}
\hline \hline Agents & \multicolumn{1}{c}{ Vesicants } & \multicolumn{1}{c}{ Irritants } & Non-tissue-damaging agents \\
\hline Hyperosmolar & Glucose $(\geq 1388 \mathrm{mOsm} / \mathrm{L})$ & Glucose $(833-1110 \mathrm{mOsm} / \mathrm{L})$ & - \\
& & Mannitol $(549-1098 \mathrm{mOsm} / \mathrm{L})$ & - \\
Vasopressor & Adrenaline $(1 \mathrm{mg} / \mathrm{mL})$ & Dopamine $(20 \mathrm{mg} / \mathrm{mL})$ & \\
& Noradrenaline $(1 \mathrm{mg} / \mathrm{mL})$ & & \\
\hline
\end{tabular}

Vesicants are agents that cause tissue necrosis even at small volumes of extravasation owing to their inherent toxicity to cells. Irritants cause inflammation without necrosis at the extravasation site. Non-tissue-damaging agents do not induce tissue injury at all.

\section{DISCUSSION}

The Pharmaceuticals and Medical Devices Agency warns that noncytotoxic agents may cause more serious extravasation injuries than cytotoxic agents. ${ }^{18,19)}$ Previous case reports have shown that hyperosmolar agents and vasopressors cause the most severe extravasation injuries of noncytotoxic agents. ${ }^{5,10)}$ However, it is unclear what osmolarity and which vasopressors specifically cause these injuries. Pharmacists should manage extravasation injuries according to the potential risks of the agents. In this study, we evaluated the extent of extravasation injuries induced by hyperosmolar agents and vasopressors and classified these agents into three categories depending on their degree of skin injury at macroscopic and histopathological levels using a rat model.

Extravasated hyperosmolar agents cause a shift in fluid from the intracellular to the extracellular space, resulting in dysfunction of cellular membranes and dysregulation of cell volume. High osmotic stress also directly leads to damage of proteins and DNA, formation of reactive oxygen species, and the induction of apoptosis. ${ }^{4)}$ Because these effects continue until the high osmolarity of extravasated solution reaches an isotonic osmolarity, extravasation of hyperosmolar agents can cause severe skin injuries even in small quantities. In this study, mannitol and glucose induced severe skin lesions in a concentration-dependent manner. At $\geq 15 \%$ (w/v) mannitol/ glucose, significantly larger peak areas and $A U C$ of lesions with erythema (but no necrosis) were observed compared with saline-injected rats. Furthermore, $\geq 25 \%(w / v)$ glucose elicited severe skin ulceration with collagen degeneration, necrosis, and inflammatory cell infiltration of epidermal, dermal and subcutaneous tissues at $24 \mathrm{~h}$. Concentrations of $15 \%(\mathrm{w} / \mathrm{v})$ mannitol, $15 \%(\mathrm{w} / \mathrm{v})$ glucose and $25 \%(\mathrm{w} / \mathrm{v})$ glucose correspond to osmolarities of 823,833 , and $1388 \mathrm{mOsm} / \mathrm{L}$, respectively. As described already, osmolarity is an important factor influencing phlebitis as well as extravasation injury. To prevent phlebitis, infusion preparations are administered via a peripheral vein at approximately $280-1000 \mathrm{mOsm} / \mathrm{L}^{11,12,20)}$ However, our results suggest that clinicians should consider the development of extravasation injury at approximately $830 \mathrm{mOsm} / \mathrm{L}$, even if this osmolarity is within the range of $280-1000 \mathrm{mOsm} / \mathrm{L}$. In the clinic, $50 \%(\mathrm{w} / \mathrm{v})$ glucose is administered intravenously via a peripheral vein to treat severe hypoglycemia with consciousness disturbance. ${ }^{21)}$ In our study, glucose at $\geq 25 \%$ ( $\mathrm{w} / \mathrm{v})$ was classified as a "vesicant" that causes tissue necrosis. Thus, clinicians should carefully monitor for the development of extravasation injury during high glucose infusions at $\geq 25 \%$ (w/v).

In glucose-injected rats, the extent of lesions was slightly milder compared with mannitol-injected rats, even at the same concentration. However, glucose is taken up into cells immediately whereas mannitol is taken up gradually. Thus, the slight differences in the extent of lesions between glucose and mannitol may be due to differences in their diffusibility into cells and metabolism. These results suggest that the degree of extravasation injury induced by hyperosmolar agents also differs according to their uptake and metabolism, even if their osmolarities are the same. By clarifying the mechanism of skin injury due to extravasation in the future, more appropriate treatments can be established for each individual medicine.

Extravasated vasopressors are thought to cause skin injury owing to local ischemia induced by vasoconstriction of veins, capillaries and vasa vasorum. In good agreement with their strength of vasoconstrictor activity, extravasation of adrenaline or noradrenaline induced similar skin lesions, whereas dopamine induced only mild lesions. ${ }^{22)}$ In future studies we aim to identify the subtypes of the vasopressor receptors involved in extravasation-induced skin injuries. According to the manufacturer's instructions, vasopressors were dissolved in acidic solutions; dopamine $\mathrm{pH}$ 3.0-5.0, adrenaline $\mathrm{pH}$ 2.3-5.0, and noradrenaline $\mathrm{pH}$ 2.3-5.0. Acid exposure commonly causes cellular desiccation, coagulative necrosis, and eschar formation. ${ }^{17,23,24)}$ Notably, several clinical case reports have shown that extravasation of less tissue invasive agents dissolved in acidic solutions, such as vancomycin ( $\mathrm{pH} 4.0$ ), doxycycline ( $\mathrm{pH}$ 1.8-3.3), and amiodarone ( $\mathrm{pH} 3.5-4.5)$, also induces skin lesions. ${ }^{25-27)}$ However, the effect of acidic $\mathrm{pH}$ on extravasation injury may be negligible, as in this study both pH 3.0 and pH 5.0 saline solutions did not induce skin lesions. Thus, the severity of injury induced by extravasated vasopressors might be determined mostly by their strength of vasoconstriction activity, rather than acidity.

In conclusion, osmolarities of 549-1098 mOsm/L mannitol and $833-1110 \mathrm{mOsm} / \mathrm{L}$ glucose can be classified as "irritants," while $\geq 1388 \mathrm{mOsm} / \mathrm{L}$ glucose can be classified as a "vesicant." As for vasopressors, adrenaline and noradrenaline can be classified as "vesicants," whereas dopamine can be classified as an "irritant" (Table 3). This information could provide reference values for identification of the risk of extravasationinduced injury by hyperosmolar agents and vasopressors.

Conflict of Interest The authors declare no conflict of interest.

\section{REFERENCES}

1) Dorr RT. Antidotes to vesicant chemotherapy extravasations. Blood Rev., 4, 41-60 (1990).

2) Sauerland C, Engelking C, Wickham R, Corbi D. Vesicant extravasation part I: mechanisms, pathogenesis, and nursing care to reduce 
risk. Oncol. Nurs. Forum, 33, 1134-1141 (2006).

3) Pérez Fidalgo JA, García Fabregat L, Cervantes A, Margulies A, Vidall C, Roila F; ESMO Guidelines Working Group. Management of chemotherapy extravasation: ESMO-EONS clinical practice guidelines. Eur. J. Oncol. Nurs., 16, 528-534 (2012).

4) Reynolds PM, MacLaren R, Mueller SW, Fish DN, Kiser TH. Management of extravasation injuries: a focused evaluation of noncytotoxic medications. Pharmacotherapy, 34, 617-632 (2014).

5) Le A, Patel S. Extravasation of noncytotoxic drugs: a review of the literature. Ann. Pharmacother., 48, 870-886 (2014).

6) The Japanese Pharmacopoeia Reference book Editorial board. The Japanese Pharmacopoeia 16th ed., Reference book. Hirokawa Publishing Co., Tokyo, pp. 3703-3706 (2011).

7) Erickson BA, Yap RL, Pazona JF, Hartigan BJ, Smith ND. Mannitol extravasation during partial nephrectomy leading to forearm compartment syndrome. Int. Braz. J. Urol., 33, 68-71, discussion, $71(2007)$

8) Lawson SL, Brady W, Mahmoud A. Identification of highly concentrated dextrose solution $(50 \%$ dextrose $)$ extravasation and treatment-a clinical report. Am. J. Emerg. Med., 31, 886.e3-886.e5 (2013)

9) O'Reilly C, McKay FM, Duffty P, Lloyd DJ. Glyceryl trinitrate in skin necrosis caused by extravasation of parenteral nutrition. Lancet, 332, 565-566 (1988)

10) Brown AS, Hoelzer DJ, Piercy SA. Skin necrosis from extravasation of intravenous fluids in children. Plast. Reconstr. Surg., 64, 145-150 (1979)

11) Everitt NJ, McMahon MJ. Peripheral intravenous nutrition. Nutrition, 10, 49-57 (1994)

12) Acra SA, Rollins C. Principles and guidelines for parenteral nutrition in children. Pediatr. Ann., 28, 113-120 (1999).

13) Peberdy MA, Callaway CW, Neumar RW, Geocadin RG, Zimmerman JL, Donnino M, Gabrielli A, Silvers SM, Zaritsky AL, Merchant R, Vanden Hoek TL, Kronick SL, American Heart Association. Part 9: post-cardiac arrest care: 2010 American heart association guidelines for cardiopulmonary resuscitation and emergency cardiovascular care. Circulation, 122 (Suppl. 3), 768-786 (2010).

14) Dorr RT, Snead K, Liddil JD. Skin ulceration potential of paclitaxel in a mouse skin model in vivo. Cancer, 78, 152-156 (1996).

15) Shibata Y, Yokooji T, Itamura R, Sagara Y, Taogoshi T, Ogawa K, Tanaka M, Hide M, Kihira K, Matsuo H. Injury due to extravasation of thiopental and propofol: risks/effects of local cooling/warming in rats. Biochem. Biophys. Rep., 8, 207-211 (2016).

16) Kokotis K. Preventing chemical phlebitis. Nursing, 28, 41-46, quiz, 47 (1998).

17) $\overline{\text { Stranz M }}$, Kastango ES. A review of $\mathrm{pH}$ and osmolarity. Int. J. Pharm. Compd., 6, 216-220 (2002).

18) Japan Council for Quality Health Care. "Medical accident Information gathering Project 25th Report.”: 〈http://www.med-safe.jp/pdf/ report_2011_1_R004.pdf), cited 7 February, 2018.

19) Japan Council for Quality Health Care. "Medical accident Information gathering Project 37th Report.": 〈http://www.med-safe.jp/pdf/ report_2014_1_R002.pdf), cited 7 February, 2018.

20) Japanese Society for Parenteral \& Enteral Nutrition. Guideline for Parenteral \& Enteral Nutrition 3rd ed. Shorinsha Co., Ltd., Tokyo, pp. 33-34 (2014).

21) Seaquist ER, Anderson J, Childs B, Cryer P, Dagogo-Jack S, Fish L, Heller SR, Rodriguez H, Rosenzweig J, Vigersky R. Hypoglycemia and diabetes: a report of a workgroup of the American diabetes association and the endocrine society. Diabetes Care, 36, 1384-1395 (2013).

22) Takaori S, Fukuda H, Akaike A. Goodman \& Gilman's the Pharmacological basis of therapeutics 10th ed., Hirokawa Publishing Co., Tokyo, pp. 279-311 (2003).

23) Ashcraft KW, Padula RT. The effect of dilute corrosives on the esophagus. Pediatrics, 53, 226-232 (1974).

24) Penner GE. Acid ingestion: toxicology and treatment. Ann. Emerg. Med., 9, 374-379 (1980).

25) Russell SJ, Saltissi S. Amiodarone induced skin necrosis. Heart, 92 , $1395(2006)$

26) Hoelen DW, Tjan DH, van Vugt R, van der Meer YG, van Zanten AR. Severe local vancomycin induced skin necrosis. Br. J. Clin. Pharmacol., 64, 553-554 (2007).

27) Hurst S, McMillan M. Innovative solutions in critical care units: extravasation guidelines. Dimens. Crit. Care Nurs., 23, 125-128 (2004). 